\title{
BMJ Open Prevalence and long-term prognostic implications of prolonged QRS duration in left ventricular hypertrophy: a population-based observational cohort study
}

\author{
Jani Rankinen (10 , ${ }^{1,2}$ Petri Haataja, ${ }^{3}$ Leo-Pekka Lyytikäinen, ${ }^{1,3,4}$ Heini Huhtala, ${ }^{5}$ \\ Terho Lehtimäki, ${ }^{1,4}$ Mika Kähönen, ${ }^{1,6}$ Markku Eskola, ${ }^{3}$ Suvi Tuohinen, ${ }^{7}$ \\ Andrés Ricardo Pérez-Riera, ${ }^{8}$ Antti Jula, ${ }^{9}$ Harri Rissanen, ${ }^{9}$ Kjell Nikus, ${ }^{1,3}$ \\ Jussi Hernesniemi ${ }^{1,3}$
}

To cite: Rankinen J, Haataja P, Lyytikäinen L-P, et al. Prevalence and longterm prognostic implications of prolonged QRS duration in left ventricular hypertrophy: a population-based observational cohort study. BMJ Open 2022;12:e053477. doi:10.1136/ bmjopen-2021-053477

\section{- Prepublication history and} additional supplemental material for this paper are available online. To view these files, please visit the journal online (http://dx.doi.org/10.1136/ bmjopen-2021-053477).

Not required.

Received 16 May 2021 Accepted 15 January 2022

Check for updates

(C) Author(s) (or their employer(s)) 2022. Re-use permitted under CC BY-NC. No commercial re-use. See rights and permissions. Published by BMJ.

For numbered affiliations see end of article.

Correspondence to Dr Jani Rankinen; jani.rankinen@tuni.fi

\section{ABSTRACT}

Objectives ECG left ventricular hypertrophy (ECG-LVH) has been associated with left ventricular dysfunction and adverse prognosis, but little is known about the prevalence and prognostic significance of different levels of QRS duration in the presence of ECG-LVH in a general population.

Design Population-based observational prospective cohort study.

Participants Nationally representative random cluster of Finnish adult population.

Methods We assessed the prevalence and long-term (median 15.9 years) prognostic significance of QRS duration in ECG-LVH, and compared the risk to individuals without ECG-LVH in a predominantly middle-aged random sample of 6033 Finnish subjects aged over 30 years (mean age 52.2, SD 14.6 years), who participated in a health examination including a 12-lead ECG.

Main outcome measures Cardiovascular and all-cause mortality, incidence of heart failure (HF).

Results ECG-LVH was present in 1337 (22.2\%) subjects; 403 of these $(30.1 \%)$ had QRS duration $\geq 100 \mathrm{~ms}$ and 100 $(7.5 \%)$ had $\geq 110 \mathrm{~ms}$. The increased risk of mortality in ECGLVH became evident after a QRS threshold of $\geq 100 \mathrm{~ms}$. After controlling for known clinical risk factors, QRS 100-109 ms was associated with increased cardiovascular (HR 1.38, $95 \% \mathrm{Cl} 1.01$ to $1.88, \mathrm{p}=0.045)$ and $\mathrm{QRS} \geq 110 \mathrm{~ms}$ with cardiovascular $(1.74,95 \% \mathrm{Cl} 1.07$ to $2.82, \mathrm{p}=0.025)$ and allcause mortality $(1.52,95 \% \mathrm{Cl} 1.02$ to $2.25, \mathrm{p}=0.039)$ in ECGLVH. The risk of new-onset HF was two-fold in subjects with QRS 100-109 ms and threefold in subjects with QRS $\geq 110$ ms, even after adjustment for incident myocardial infarction within the follow-up. When the prognosis was compared with subjects without ECG-LVH, subjects with ECG-LVH but QRS duration $<100$ ms displayed similar mortality rates with or without ECG-LVH but higher rates of incident HF.

Conclusions In ECG-LVH, the risk of excess mortality and new-onset HF markedly increases with longer QRS duration, but even QRS duration within normal limits in ECG-LVH carried a risk of HF compared with the risk in individuals without ECG-LVH.
Strengths and limitations of this study

- To our knowledge, this is the first population-wide study to explore the prognostic implications of QRS duration in ECG left ventricular hypertrophy, an easily recognised ECG finding which could aid in screening for cardiovascular (CV) risk and mortality.

- A large nationally representative random cluster of Finnish adult population was followed for median of 15.9 years for overall and CV mortality and incidence of heart failure.

- All subjects participated in a comprehensive health examination, enabling well-defined baseline characteristics.

- Absence of imaging data is a study limitation as some of the subjects may have had an underlying clinically asymptomatic cardiac disease not evident at the baseline examination, although imaging data are not necessarily available in general practice in which the initial screening would normally take the place.

\section{INTRODUCTION}

Assessment of left ventricular hypertrophy $(\mathrm{LVH})$ in the standard 12-lead ECG is recommended for every hypertensive individual ${ }^{12}$ and ECG-LVH is predictive of future cardiovascular (CV) events independently of echocardiography findings. ${ }^{2}$ The principal findings in ECG-LVH are increases of QRS amplitude and duration, and abnormalities of ST-segment with T-wave changes. ${ }^{3}$ While many previous studies have been dedicated to assess the prognostic relevance of different voltage criteria-based definitions for ECG-LVH, ${ }^{4-7}$ the prevalence and prognostic significance of QRS duration in ECGLVH has not been well established in general 
population. Literature regarding the prognostic significance of QRS duration in a general population is also somewhat conflicting as a mild conduction delay (QRS duration 100-119 ms) was associated with increased risk of mortality even after adjustment for LVH in one study, ${ }^{8}$ but not after adjustment for known cardiac risk factors including $\mathrm{LVH}$ in another study. ${ }^{9}$

Therefore, the aim of this study was to evaluate the prevalence and prognostic value of QRS duration in individuals with ECG-LVH in a nationally representative general population sample. In addition, we aimed at comparing the prognostic significance of different levels of QRS duration between individuals with and without ECG-LVH. We tested the hypothesis that QRS duration has prognostic relevance when associated with ECG-LVH, and that this easily recognised ECG finding could further stratify risk in patients with ECG-LVH and aid in screening for risk of CV mortality and for early identification of new-onset heart failure (HF).

\section{METHODS}

\section{Study population}

This study was conducted as part of the ${ }^{10}$ Health 2000 survey, which consists of a random sample of a predominantly Caucasian general population with applicable phenotype data collected at baseline and during 16.5 years of total follow-up. The survey was carried out in 2000-2001, and a representative stratified random cluster sample of the Finnish population was examined. The purpose of the survey was to provide up-to-date epidemiological data of major public health problems in Finland. The implementation of the survey was described in detail elsewhere. ${ }^{10}$ Sample comprised 8028 individuals (3637 men and 4391 women) aged 30 years or older, of whom $79 \%$ (6 354 individuals; 2876 men and 3478 women) participated in the health examination. ECGs were obtained successfully in 6318 individuals (99\%). For this study, 19 subjects were excluded because of missing ECGs. We also excluded subjects with paced rhythm $(n=13)$, left bundle branch block ( $\mathrm{n}=47$; defined by the Strauss definition ${ }^{11}$ ), incomplete and complete right bundle branch block $(n=136)$, left anterior fascicular block $(n=69)$ and Wolff-Parkinson-White pattern $(\mathrm{n}=1)$ (figure 1). After these exclusions, the study population consisted of 6033 subjects: 3320 women and 2713 men (mean age 52.2, SD 14.6 years).

\section{Collection of clinical phenotype data}

After a home interview, a comprehensive health examination including questionnaires, measurements and physician's physical examination was performed. The National Care Register for Health Care and the national register on rights to reimbursements for medication costs were linked to the ${ }^{10}$ Health 2000 Survey data. The health examination included measurements of height, weight, body mass index (BMI). Blood pressure was measured two times with a mercury sphygmomanometer (Mercuro 300, Speidel \& Keller, Juningen, Germany) from the right arm. Hypertension was defined as a clinic average blood pressure $\geq 140 / 90 \mathrm{~mm} \mathrm{Hg}$ or right to drug reimbursements for hypertension. Laboratory tests included measurements for serum glucose level and cholesterol levels. Diabetes mellitus was defined as a serum glucose level of $7.0 \mathrm{mmol} / \mathrm{L}$ or greater or a history of the use of oral hypoglycaemic agents or insulin therapy. Low-density

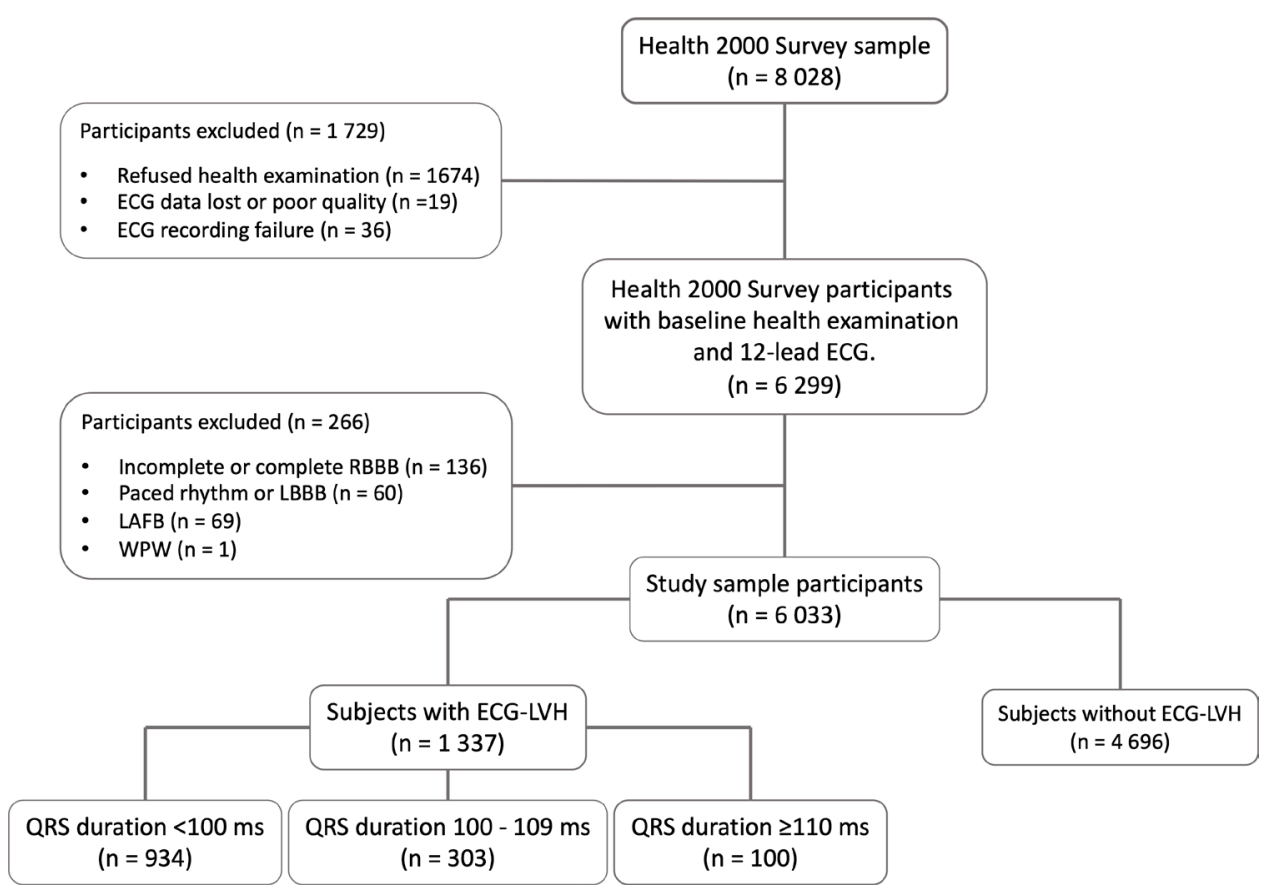

Figure 1 Study flow chart. LVH, left ventricular hypertrophy LAFB = left anterior fascicular block; LBBB = left bundle branch block; RBBB = right bundle branch block; WPW = Wolff-Parkinson-White 
lipoprotein cholesterol was calculated with the Friedewald formula. Smoking was defined as daily use of tobacco products. Standard 12-lead ECGs were recorded in the resting supine position by MAC 5000 recorders (Marquette Hellige, Freiburg, Germany and Milwaukee, Wisconsin, USA) and stored as digital data on a Marquette MUSE CV 5B system (Marquette Hellige). All ECGs were read, and the computerised diagnoses and measurements corrected if needed, by a physician experienced with ECG before being stored in the database. The ECGs were recorded and printed using a paper speed of $50 \mathrm{~mm} / \mathrm{s}$. The maximal filter setting of the system (150 hertz) was used. Minnesota coding was performed at the Institute of Cardiology, Kaunas Medical Academy, Lithuania, by two investigators who were blinded to the clinical data of the patient. Abnormalities identified visually in the ECG strips were coded in accordance with the Minnesota coding scheme. ${ }^{12}$ ECG-LVH was identified with Cornell $\left(\mathrm{S}_{\mathrm{V} 3}+\mathrm{R}_{\mathrm{aVL}}>2.0 \mathrm{mV}\right.$ for women, $>2.8 \mathrm{mV}$ for $\left.\mathrm{men}^{13}\right)$ and/ or Minnesota (code 3-1 which includes $\mathrm{R}_{\mathrm{aVL}}$ amplitude criterion: $\mathrm{R}_{\mathrm{V} 5}$ or $\mathrm{R}_{\mathrm{V} 6}>2.6 \mathrm{mV}$, or $\mathrm{R}_{\mathrm{I}}$ or $\mathrm{R}_{\mathrm{II}}$ or $\mathrm{R}_{\mathrm{III}}$ or $\mathrm{R}_{\mathrm{aVF}}$ $>2.0 \mathrm{mV}$, or $\mathrm{R}_{\mathrm{aVL}}>1.2 \mathrm{mV}$; and code 3-3 which includes the Sokolow-Lyon criteria: $\mathrm{R}_{\mathrm{T}}>1.5 \mathrm{mV}$ but $\leq 2.0 \mathrm{mV}$, or $\mathrm{R}_{\mathrm{v} 5}+$ $\mathrm{S}_{\mathrm{V} 1}>3.5 \mathrm{mV}$, or $\mathrm{R}_{\mathrm{v} 6}+\mathrm{S}_{\mathrm{v} 1}>3.5 \mathrm{mV}^{12}$ ) voltage criteria. $\mathrm{ECG}-$ LVH was considered positive if any of the criteria was met, and negative if none of criteria was met.

Classification for coronary heart disease (CHD) required at least one of the following: diagnosis of myocardial infarction (MI) and/or angina pectoris during the field health examination by the examining physician, $\mathrm{Q}$ waves in the resting ECG, prior hospitalisation for CHD (International Classification of Diseases (ICD)-10 codes I20-I25), a history of coronary revascularisation procedure, the right to drug reimbursements for $\mathrm{CHD}$, or the use of nitroglycerine combined with an anticoagulant, acetyl salicylic acid or betablocker. Classification for previous MI required either a clinical diagnosis of old MI by the examining physician, $Q$ waves in the resting ECG, or a previous discharge diagnosis of MI (ICD-10 codes I21-I22). Old MI was defined as a positive history of the condition in the medical records or old MI on ECG, or typical self-reported history of MI treated in a hospital. Q waves indicating probable previous MI included Minnesota codes 1.1-1.3. HF classification required a clinical diagnosis by the examining physician at the baseline health examination or a previous discharge diagnosis of HF (ICD-10 code I50) or the right to drug reimbursements for HF.

\section{Main exposure and outcome variables}

The main exposure variable of this study was QRS duration in association with ECG-LVH. We also tested for the prognostic significance of QRS duration when unassociated with ECG-LVH. Main prognostic outcomes were CV mortality, all-cause mortality and new-onset HF during a follow-up starting from the baseline examination (between 2000 and 2001) until the end of 2015 (total follow-up time 16.5 years, median 15.9 years).

New-onset HF was defined as hospitalisation for HF from the Care Register for Healthcare, new right to drug reimbursements for $\mathrm{HF}$, or $\mathrm{HF}$ as the primary underlying or immediate cause of death from the Causes of Death Register. For this particular endpoint, participants with prevalent HF or CHD or anginal symptoms at the baseline examination were excluded from the analysis when studying QRS duration as an independent risk factor for new-onset HF. The follow-up information was gathered by linking the personal identity code from the ${ }^{10}$ Survey database to the Care Register for Healthcare and the Causes of Death register, maintained by Statistic Finland, which records 100\% of deaths of Finnish citizens in Finland. Diagnoses are registered in these registers by the treating physicians with codes defined in ICD-10. The Finnish Care Register for Healthcare has been shown to be valid in identifying major CHD events, ${ }^{14}$ and has been shown to be valid in identifying HF diagnoses with high positive and negative predictive values and can be reliably used for research purposes. ${ }^{15}$ The follow-up information was available for all subjects.

\section{STATISTICAL ANALYSES}

Proportions across groups were compared with the chisquare test or Fisher's exact test. The distribution of QRS duration in the study population, was visualised by a density plot. The linearity of the association of QRS duration and mortality was checked in a spline model in subjects with ECG-LVH. This showed a clear deviation from linearity with the risk of death increasing clearly above QRS duration of $100 \mathrm{~ms}$. In order to demonstrate the results in clinical context, the population was divided in three subgroups with different QRS durations: $<100$ ms, $100-109 \mathrm{~ms}$ and $\geq 110 \mathrm{~ms}$. Prognostic implications of QRS duration were studied across these ECG-LVH groups and also further comparing the results to subjects without ECG-LVH. Unadjusted survival to each endpoint was assessed using the Kaplan-Meier method. Adjusted HRs were calculated by univariate and multivariable proportional Cox regression model analysis. Multivariable analysis included the following clinical parameters: age, sex, hypertension, diabetes mellitus, CHD, MI, HF, ST-depression lead V5, smoking, BMI and low-density lipoprotein cholesterol. Further adjustment for incident MI within the follow-up was included in the multivariable Cox regression analysis when studying the risk of newonset HF. Death from non-CV causes was considered as a competing event to $\mathrm{CV}$ death. To take into account this competing risk, additional Fine and Gray subdistribution hazard modelling ${ }^{16}$ was applied to control for possible confounding due to censoring by competing events in the survival analysis when analysing the association between QRS time and CV mortality. There were no significant changes in the results, indicating that possible effect of exposure variables on the rate of competing events did not have significant effect on the observed risk estimates. We also tested for interaction between the QRS duration and sex by introducing their product as an interaction term. Interaction for QRS duration and prevalent CHD was also tested similarly. Interaction analyses showed no 


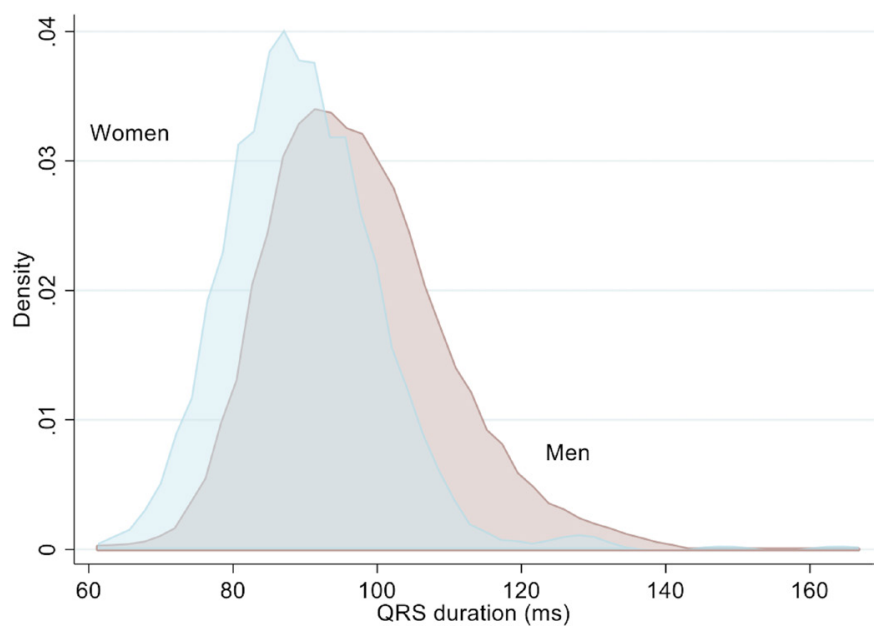

Figure 2 Distribution of QRS duration in subjects with ECG left ventricular hypertrophy in the general population

interaction between QRS duration and sex associating with the risk of mortality or new-onset HF, or between QRS duration and CHD associating with the risk of mortality among subjects with ECG-LVH ( $>0.1$ for both). A $p<0.05$ was considered to be statistically significant.

\section{Patient and public involvement}

Patients and the public were not involved in the design, data provision, analysis or publication of the study.

\section{RESULTS}

Of the entire study population, 1337 subjects had ECGLVH by any of the criteria (22.2\%; 637 women and 700 men). Among subjects with LVH, men had longer QRS duration than women (mean $96 \mathrm{~ms}$ (SD $11 \mathrm{~ms}$ ) vs $90 \mathrm{~ms}$ (SD $11 \mathrm{~ms}$ ), $\mathrm{p}<0.001$ for difference). The distribution of study subjects with ECG-LVH according to QRS duration is shown in figure 2.

At baseline (table 1), subjects with ECG-LVH were associated with every single $\mathrm{CV}$ risk factor and $\mathrm{CV}$ disease except for smoking as compared those without ECG-LVH $(\mathrm{p}<0.001)$. The majority $(69.9 \%)$ of subjects with ECGLVH had a QRS-duration of $<100 \mathrm{~ms}, 22.7 \%$ had $100-109$ $\mathrm{ms}$ and $7.5 \% \geq 110 \mathrm{~ms}$. Those with QRS duration $\geq 110$ ms were more often male and had a history of ischaemic heart disease or prior MI. Clinical characteristics in a population matched by QRS duration is provided in online supplemental table 1.

Association between QRS duration in ECG-LVH and mortality During the median 15.9 years' follow-up, $19.5 \%$ of subjects died $(n=1174 / 6033)$. Of these, 571 (48.6 \% of all deaths) deaths were due to CV causes. Subjects with ECG-LVH met more often the primary endpoint than those without ECG-LVH $(p<0.001)$. According to the unadjusted spline model (figure 3), the association between QRS duration in ECG-LVH and overall mortality seemed non-linear, with increased mortality rates after the threshold of 100 ms for QRS duration. Supporting this, adjusting for other clinical factors, subjects with ECG-LVH with QRS $<100$ $\mathrm{ms}$ showed no significant difference in all-cause or $\mathrm{CV}$ mortality when compared with subjects with no ECG-LVH and a normal QRS duration $(<100 \mathrm{~ms})$ in the general population (HR $1.11,95 \%$ CI 0.89 to $1.38, p=0.350$ for CV mortality and HR $0.96,95 \%$ CI 0.83 to $1.11, p=0.599$ for all-cause mortality). In other words, subjects with a

Table 1 Clinical characteristics and prevalence of baseline comorbidities in the subjects with ECG left ventricular hypertrophy classified by QRS duration

\begin{tabular}{|c|c|c|c|c|c|c|c|c|}
\hline & \multirow{2}{*}{\multicolumn{2}{|c|}{$\begin{array}{l}\text { Reference } \\
\text { (No ECG-LVH and } \\
\text { QRS duration }<100 \mathrm{~ms} \text { ) } \\
\text { ( } \mathrm{n}=3785)\end{array}$}} & \multicolumn{6}{|c|}{ With ECG-LVH } \\
\hline & & & \multicolumn{2}{|c|}{$\begin{array}{l}\text { QRS }<100 \mathrm{~ms} \\
(\mathrm{n}=934)\end{array}$} & \multicolumn{2}{|c|}{$\begin{array}{l}\text { QRS 100-109 ms } \\
(n=303)\end{array}$} & \multicolumn{2}{|c|}{$\begin{array}{l}\text { QRS } \geq 110 \mathrm{~ms} \\
(n=100)\end{array}$} \\
\hline & $\mathrm{N} /($ mean) & $\% /(S D)$ & $\mathrm{N} /($ mean) & $\% /($ SD) & $\mathrm{N} /$ (mean) & $\% /($ SD) & $\mathrm{N} /($ mean) & $\% /$ (SD) \\
\hline Male & 1300 & 34.3 & 410 & $43.9^{*}$ & 207 & 68.3 & 83 & $83.0+$ \\
\hline Age (years) & $(51.1)$ & $(14.0)$ & $(57.9)$ & $(15.5)^{\star}$ & (54.9) & $(15.7)$ & $(57.0)$ & (16.9) \\
\hline $\mathrm{BMI}\left(\mathrm{kg} / \mathrm{m}^{2}\right)$ & (26.8) & (4.8) & $(26.9)$ & $(4.5)$ & (27.4) & (4.4) & $(27.1)$ & (3.8) \\
\hline Current smoking & 845 & 22.3 & 148 & $15.8^{\star}$ & 64 & 21.1 & 17 & 17.0 \\
\hline LDL cholesterol (mmol/L) & (3.7) & $(1.0)$ & (3.9) & $(1.1)^{\star}$ & $(3.7)$ & $(1.0)$ & (3.8) & $(0.9)$ \\
\hline QRS duration (ms) & (86) & (7) & (87) & $(7)^{\star}$ & (103) & (3) & (118) & (8) $\dagger$ \\
\hline Hypertension & 1545 & 41.0 & 616 & $66.1^{*}$ & 194 & 64.0 & 71 & 71.0 \\
\hline Diabetes mellitus & 190 & 5.0 & 67 & $7.2^{*}$ & 30 & 9.9 & 5 & 5.0 \\
\hline Coronary heart disease & 270 & 7.1 & 141 & $15.1^{*}$ & 46 & 15.2 & 26 & $26.0 \dagger$ \\
\hline Myocardial infarction & 81 & 2.1 & 49 & $5.2^{*}$ & 18 & 5.9 & 15 & $15.0 \dagger$ \\
\hline Heart failure & 51 & 1.3 & 41 & $4.4^{*}$ & 11 & 3.6 & 7 & 7.0 \\
\hline
\end{tabular}

${ }^{*} \mathrm{P}<0.05$ for difference between subgroups of QRS duration $<100 \mathrm{~ms}$ with or without left ventricular hypertrophy.

$\dagger P<0.05$ for difference between three QRS duration subgroups with left ventricular hypertrophy.

BMI, body mass index; LDL, Low-density lipoprotein; LVH, left ventricular hypertrophy. 


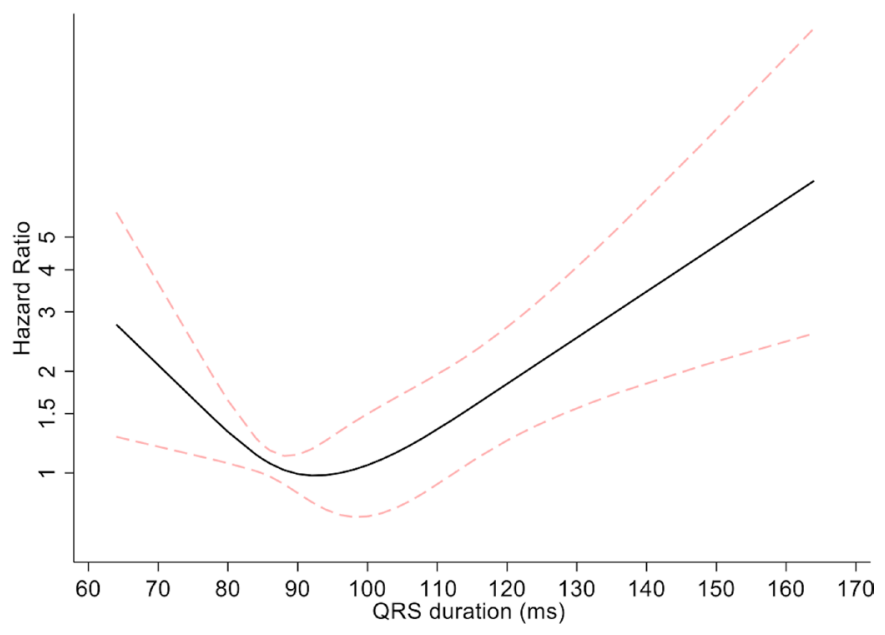

Figure 3 Unadjusted HRs for QRS duration and all-cause mortality in subjects with ECG left ventricular hypertrophy. Dotted lines are 95\% confidence limits of the resulting HRs. the risk for mortality increases along with longer QRS duration

QRS duration $<100 \mathrm{~ms}$ displayed similar mortality rates whether ECG-LVH was present or not.

When analysing only subjects with ECG-LVH $(n=1337)$ and using subjects with normal QRS duration $(<100 \mathrm{~ms})$ as a reference group (table 2), the risk of CV mortality was significantly higher among subjects with QRS 100-109 ms (HR $1.38,95 \%$ CI 1.01 to $1.88, \mathrm{p}=0.045$ ) or with QRS $\geq 110 \mathrm{~ms}$ (HR $1.74,95 \%$ CI 1.07 to $2.82, \mathrm{p}=0.025$ ). This same trend was also reflected in the increased risk for all-cause mortality in these groups (HR 1.22, 95\% CI 0.96 to $1.55, \mathrm{p}=0.112$ for QRS $100-109 \mathrm{~ms}$, and HR $1.52,95 \%$ CI 1.02 to $2.25, \mathrm{p}=0.039$ for $\mathrm{QRS} \geq 110 \mathrm{~ms}$ ), respectively. While the visualisation of the unadjusted spline model suggested that the lower levels of QRS duration could associate with increased mortality (figure 3 ), this was not true after adjustment for age and clinical risk factors (HR $0.95,95 \%$ CI 0.66 to $1.37, \mathrm{p}=0.781$ for $\mathrm{QRS}$ duration $<80$ $\mathrm{ms}$ as compared with QRS duration 80-99 ms).

\section{Association between QRS duration in ECG-LVH and the risk of new-onset HF}

Among the 5904 subjects with no HF at baseline, 382 subjects $(6.5 \%)$ developed new-onset HF during the follow-up. Subjects with ECG-LVH developed more often incident HF $(11.1 \%)$ than those without ECGLVH (5.0\%; $\mathrm{p}<0.001)$. ECG-LVH was associated with an increased risk of new-onset $\mathrm{HF}$ in all the categories of QRS duration, even among subjects with a QRS $<100 \mathrm{~ms}$ (HR 1.40, 95\% CI 1.06 to $1.86, \mathrm{p}=0.019$ ), when compared with the subjects with no ECG-LVH and QRS $<100 \mathrm{~ms}$ in the general population.

When analysing only subjects with ECG-LVH (n=1 337) and using subjects QRS duration $<100 \mathrm{~ms}$ as a reference group (table 2), the risk of new-onset HF was significantly higher among subjects with QRS 100-109 ms (HR 2.18, 95\% CI 1.32 to $3.61, \mathrm{p}=0.003$ ) and with $\mathrm{QRS} \geq 110 \mathrm{~ms}$ (HR $3.39,95 \%$ CI 1.60 to $7.17, \mathrm{p}=0.001)$. Further adjustment for incident MI within the follow-up had no meaningful impact on results-the risk of HF was 1.83 (95\% CI 1.12

Table 2 Adjusted Cox proportional hazard analysis for mortality and incident heart failure events in subjects with ECG left ventricular hypertrophy in three QRS duration subgroups

\begin{tabular}{|c|c|c|c|c|c|c|c|}
\hline & \multirow{2}{*}{$\begin{array}{l}\text { No of deaths/incident } \\
\text { HFs (\%) }\end{array}$} & \multicolumn{3}{|c|}{ Age and gender adjusted } & \multicolumn{3}{|c|}{ Multivariable $^{*}$ adjusted } \\
\hline & & HR & $95 \% \mathrm{Cl}$ & $P$ value & HR & $95 \% \mathrm{Cl}$ & $P$ value \\
\hline \multicolumn{8}{|c|}{ Cardiovascular Mortality } \\
\hline \multicolumn{8}{|l|}{ QRS duration } \\
\hline$<100 \mathrm{~ms}$ & $135(14.5 \%)$ & 1 & & & 1 & & \\
\hline $100-109 \mathrm{~ms}$ & $56(18.5 \%)$ & 1.39 & 1.00 to 1.92 & 0.048 & 1.38 & 1.01 to 1.88 & 0.045 \\
\hline$\geq 110 \mathrm{~ms}$ & $22(22.0 \%)$ & 1.91 & 1.20 to 3.04 & 0.007 & 1.74 & 1.07 to 2.82 & 0.025 \\
\hline \multicolumn{8}{|l|}{ All-cause mortality } \\
\hline \multicolumn{8}{|l|}{ QRS duration } \\
\hline$<100 \mathrm{~ms}$ & 257 (27.5\%) & 1 & & & 1 & & \\
\hline $100-109 \mathrm{~ms}$ & $86(28.4 \%)$ & 1.17 & 0.91 to 1.51 & 0.222 & 1.22 & 0.96 to 1.55 & 0.112 \\
\hline$\geq 110 \mathrm{~ms}$ & $32(32.0 \%)$ & 1.54 & 1.05 to 2.24 & 0.026 & 1.52 & 1.02 to 2.25 & 0.039 \\
\hline \multicolumn{8}{|l|}{ New-onset HF } \\
\hline \multicolumn{8}{|l|}{ QRS duration } \\
\hline$<100 \mathrm{~ms}$ & 87 (9.3\%) & 1 & & & 1 & & \\
\hline $100-109 \mathrm{~ms}$ & $38(12.5 \%)$ & 1.83 & 1.09 to 3.06 & 0.023 & 2.18 & 1.32 to 3.61 & 0.003 \\
\hline$\geq 110 \mathrm{~ms}$ & $23(23.0 \%)$ & 4.36 & 2.11 to 9.02 & $<0.001$ & 3.39 & 1.60 to 7.17 & 0.001 \\
\hline
\end{tabular}

*Adjusted for age, sex, coronary heart disease, myocardial infarction, heart failure, hypertension, ST-depression in lead V5, diabetes mellitus, smoking, body mass index and low-density lipoprotein cholesterol.

$\mathrm{HF}$, heart failure. 
to 2.97, $\mathrm{p}=0.015$ ) for QRS 100-109 ms, and 4.03 (95\% CI 1.98 to $8.21, \mathrm{p}<0.001$ ) for $\mathrm{QRS} \geq 110 \mathrm{~ms}$.

\section{Prognostic significance of QRS duration unassociated with ECG-LVH}

Among 4696 subjects without meeting any of the predefined ECG-LVH criteria, 3785 subjects $(80.6 \%)$ had QRS duration <100 ms, $750(16.0 \%)$ had 100-109 $\mathrm{ms}$, and $161(3.4 \%)$ had QRS duration $\geq 110 \mathrm{~ms}$ (online supplemental table 1). When none of the ECG-LVH criteria was met, subjects with QRS 100-109 ms or QRS $\geq 110$ ms displayed no increased risk of mortality or $\mathrm{HF}$ as compared with those with QRS duration $<100 \mathrm{~ms}$ (online supplemental tabel 2).

Supporting the impaired prognosis of prolonged QRS duration associated with ECG-LVH, when analysing subjects with $Q R S \geq 110 \mathrm{~ms}$ in the population $(\mathrm{n}=261)$ and adjusting for clinical factors, subjects with ECG-LVH with QRS $\geq 110 \mathrm{~ms}$ had almost a two-fold risk of all-cause (HR $1.81,95 \%$ CI 1.03 to $3.18, \mathrm{p}=0.039$ ) and CV mortality (HR $1.97,95 \%$ CI 1.01 to $3.88, \mathrm{p}=0.048$ ) and over fivefold risk of incident HF (HR 5.23, 95\% CI 1.62 to 16.94, $\mathrm{p}=0.006$ ) when compared with subjects with QRS $\geq 110 \mathrm{~ms}$ but not meeting any of the predefined ECG-LVH criteria.

\section{DISCUSSION}

The main finding of this study is that among subjects with ECG-LVH, the risk of new-onset HF and mortality significantly increases with longer QRS duration. The higher mortality risk associated with QRS duration in ECG-LVH was driven by a strong association with CV mortality, and even subjects with ECG-LVH but normal QRS duration $(<100 \mathrm{~ms})$ had a significantly higher risk for new-onset HF when compared with subjects without ECG-LVH with normal QRS duration $(<100 \mathrm{~ms})$. Men have longer QRS duration when compared with women, but all observed associations were independent of sex and several known clinical risk factors.

A valid concern of the diagnostic accuracy of ECG-LVH pattern may arouse as $22.2 \%$ of the population met any of the predefined LVH criteria. In the Coronary Heart Disease study ${ }^{17}$ the prevalence of ECG-LVH was $31.3 \%$, and in the Copenhagen City Heart Study voltage-only LVH was seen in $23.1 \%$ of men. ${ }^{18}$ In addition, $19.6 \%$ had LVH by any of predefined ECG criteria in the Atherosclerosis Risk in Communities Study, ${ }^{19}$ and the specificity of each ECG-LVH criterion used in the current study was $>92 \%$ in reference to LVH defined by cardiac MRI in the Multi-Ethnic Study of Atherosclerosis cohort. ${ }^{20}$ Nevertheless the diagnostic accuracy of ECG-LVH, we have demonstrated in this study that QRS duration can be used as a risk marker in ECG-LVH as increased risk of mortality was only seen in subjects with prolonged QRS duration, and in fact ECG-LVH was related to an increased risk of incident HF irrespective of QRS duration.

As expected, the overall prevalence of a QRS duration $\geq 110 \mathrm{~ms}$ in ECG-LVH was lower $(7.5 \%)$ in the general population than what has been previously reported in selected patient cohorts; in a study dealing with hypertension and HF, the prevalence was $21.7 \%{ }^{21}$ In line, the overall prevalence of a QRS duration $\geq 100 \mathrm{~ms}$ associated with ECG-LVH was lower in our study $(30.1 \%)$ than what was reported in an earlier report of veterans from the Palo Alto Veterans Administration Healthcare System. In that study, the prevalence of a QRS duration $>100 \mathrm{~ms}$ in ECG$\mathrm{LVH}$ was $43.8 \%$ and the finding was linked to increased $\mathrm{CV}$ mortality, but the study sample consisted only of men. ${ }^{6}$

Supporting our original hypothesis, when associated with ECG-LVH, prolonged QRS duration was a particularly strong risk factor for CV mortality and incident HF even after adjusting for relevant clinical risk factors including prevalent ischaemic heart disease. Association between QRS duration and increased risk of mortality was also observed in a prior study of hypertensive patients with ECG-LVH in a setting of aggressive hypertensive therapy, ${ }^{22}$ though the subjects in this study were clearly younger and predominantly middle-aged. In another report of the same cohort the risk of incident HF was observed only in subjects with ECG-LVH and QRS duration $\geq 110 \mathrm{~ms}$ during a mean follow-up of 4.7 years. ${ }^{21}$ Our study confirms the findings of the previous studies in a population-wide cohort with over 15 years of observation, and we are further reporting that subjects with ECG-LVH have increased risk of novel HF even when QRS duration is within normal limits $(<100 \mathrm{~ms})$, but the risk of incident $\mathrm{HF}$ and mortality strongly increases with longer QRS duration and even a mild conduction delay (QRS duration 100-109 ms) was associated with a twofold risk and $\mathrm{QRS} \geq 110 \mathrm{~ms}$ with a threefold risk of new-onset HF in subjects with ECG-LVH, even after adjustment for incident MI.

Although the unadjusted spline model indicated the shorter QRS duration in ECG-LVH could be associated with increased mortality, this was not true after adjustment for clinical risk factors. The result is in line with a previous study that showed narrow QRS duration had no prognostic relevance in middle-aged men. ${ }^{23}$ The higher mortality risk associated with prolonged QRS duration in this study may be related to left ventricular structural remodelling as prolonged QRS has been shown to correlate with increased left ventricular mass, ${ }^{22}{ }^{24-26}$ and previous study findings have established a linear relationship between left ventricular mass and CV mortality. ${ }^{27-31}$ In special patient cohorts, QRS duration may implicate other associated pathology as inverse relationship between QRS duration and left ventricular mass was found in a recent study investigating patients with hypertrophic cardiomyopathy. ${ }^{32}$ However, in an unselected general population, QRS duration correlates with $\mathrm{LVH}$, and at the population level the most important risk factor for LVH is hypertension. ${ }^{33}$ Possible pathophysiological mechanism for the relation of QRS duration and HF may also be related to increased left ventricular mass and structural remodelling. In previous studies, prolonged QRS duration was recognised as a specific indicator of 
left ventricular dysfunction, ${ }^{34}$ and in the Cardiovascular Health Study ${ }^{35}$ increased left ventricular mass was independently associated with decreased left ventricular function within the follow-up in elderly subjects with normal left ventricular ejection fraction at baseline. In the MultiEthnic Study of Atherosclerosis, ${ }^{26}$ QRS duration $\geq 100 \mathrm{~ms}$ was associated with an increased incidence of HF, but the risk was attenuated to non-significance after adjustment for cardiac MRI measures of left ventricular structure, suggesting that prolonged QRS duration is a potentially useful marker to detect left ventricular remodelling that may predispose to $\mathrm{HF}$.

Some study limitations need to be pointed out. First of all, even though the baseline health examination findings enabled the exclusion of subjects with either anginal symptoms or previously known or symptomatic HF and apparent ischaemic heart disease, absence of imaging data is a study limitation typical of a population study and thus the possibility of underlying silent cardiac conditions, such as reduced left ventricular function without symptomatic HF, could not be excluded. However, imaging data are not necessarily available in clinical practice when dealing with patients with prolonged QRS duration. The purpose of this study was to evaluate the prognostic implications of QRS duration using the information that is normally available in general practice in which the screening would normally take the place. We think that the large study population representing a wide age range from both genders, well-defined baseline characteristics, and long follow-up gives strength to our study findings.

\section{CONCLUSIONS}

In a nationally representative population study of predominantly middle-aged subjects with over 15 years of follow-up, prolonged QRS duration was associated with increased risk of mortality and with new-onset HF in subjects with ECG-LVH independently of several baseline variables. The risk was more pronounced with longer QRS duration.

This study may offer a couple of clinical implications. In the presence of even mildly prolonged QRS duration in the standard 12-lead ECG, ECG evidence of LVH ought to be carefully scrutinised as these patients were associated with impaired prognosis, and the presence of prolonged QRS duration in combination of ECG-LVH should alert physicians to perform careful cardiac evaluation even in absence of CV symptoms. Future studies should focus on whether clinical or imaging follow-up, such as a routine echocardiographic control, is prudent and cost-effective for early identification of asymptomatic heart disease in individuals with prolonged QRS duration with evidence of ECG-LVH.

\section{Author affiliations}

${ }^{1}$ Faculty of Medicine and Health Technology, Tampere University, and Finnish Cardiovascular Research Center, Tampere, Finland

${ }^{2}$ Department of Internal Medicine, Kanta-Häme Central Hospital, Hämeenlinna, Finland
${ }^{3}$ Heart Center, Department of Cardiology, Tampere University Hospital, Tampere, Finland

${ }^{4}$ Department of Clinical Chemistry, Tampere University Hospital, Tampere, Finland ${ }^{5}$ Faculty of Social Sciences, Tampere University, Tampere, Finland

${ }^{6}$ Department of Clinical Physiology, Tampere University Hospital, Tampere, Finland ${ }^{7}$ Heart and Lung Center, Helsinki University Central Hospital, Helsinki, Finland ${ }^{8}$ Design of Studies and Scientific Writing Laboratory, Faculdade de Medicina do ABC, Santo Andre, São Paulo, Brazil

${ }^{9}$ Finnish Institute for Health and Welfare, Helsinki/Turku, Finland

Acknowledgements The authors thank the personnel in the field, support organisations and participants of the ${ }^{10}$ Survey for their contributions.

Contributors JR conceived the original idea, performed the original analyses and wrote the original manuscript. $\mathrm{HH}$ provided the figures and helped with the statistics. AJ and HR provided the original Health 2000 Survey data and L-PL provided data curation. PH, TL, ME, ST and ARP-R helped supervise the project. MK supervised the project and helped to shape the final manuscript. KN and JH participated in writing and revising the manuscript and administrated the project. As guarantor, JR accepts full responsibility for the conduct of the study, had access to the data, and controlled the decision to publish.

Funding This study was supported by the Finnish Foundation for Cardiovascular Research (no grant number) and Finska Läkaresällskapet (no grant number).

Competing interests None.

Patient consent for publication Not applicable.

Ethics approval The study protocol of the survey was approved by the Epidemiology Ethics Committee of the Helsinki and Uusimaa Hospital District (407/ E3/2000). All participants in the survey signed an informed consent both before the health interview and at the beginning of the health examination.

Provenance and peer review Not commissioned; externally peer reviewed.

Data availability statement No data are available. Data are not available due to legal (GDPR) restrictions and due to data protection protocol of the survey.

Supplemental material This content has been supplied by the author(s). It has not been vetted by BMJ Publishing Group Limited (BMJ) and may not have been peer-reviewed. Any opinions or recommendations discussed are solely those of the author(s) and are not endorsed by BMJ. BMJ disclaims all liability and responsibility arising from any reliance placed on the content. Where the content includes any translated material, BMJ does not warrant the accuracy and reliability of the translations (including but not limited to local regulations, clinical guidelines, terminology, drug names and drug dosages), and is not responsible for any error and/or omissions arising from translation and adaptation or otherwise.

Open access This is an open access article distributed in accordance with the Creative Commons Attribution Non Commercial (CC BY-NC 4.0) license, which permits others to distribute, remix, adapt, build upon this work non-commercially, and license their derivative works on different terms, provided the original work is properly cited, appropriate credit is given, any changes made indicated, and the use is non-commercial. See: http://creativecommons.org/licenses/by-nc/4.0/.

ORCID iD

Jani Rankinen http://orcid.org/0000-0002-5796-6557

\section{REFERENCES}

1 Unger T, Borghi C, Charchar F, et al. International Society of hypertension global hypertension practice guidelines. Hypertens 2020;2020:1334-57.

2 Williams B, Mancia G, Spiering W, et al. ESC/ESH guidelines for the management of arterial hypertension. Eur Heart $J$ 2018;2018:3021-104.

3 Hancock EW, Deal BJ, Mirvis DM, et al. AHA/ACCF/HRS recommendations for the standardization and interpretation of the electrocardiogram: Part V: electrocardiogram changes associated with cardiac chamber hypertrophy: a scientific statement from the American heart association electrocardiography and arrhythmias Committee, Council on clinical cardiology; the American College of cardiology Foundation; and the heart rhythm. Endorsed by the International Society for Computerized Electrocardiology 2009;119:e251-61.

4 Cuspidi C, Facchetti R, Bombelli M, et al. Accuracy and prognostic significance of electrocardiographic markers of left ventricular 
hypertrophy in a general population: findings from the Pressioni Arteriose Monitorate E Loro Associazioni population. J Hypertens 2014;32:921-8.

5 Porthan K, Niiranen TJ, Varis J, et al. Ecg left ventricular hypertrophy is a stronger risk factor for incident cardiovascular events in women than in men in the general population. J Hypertens 2015;33:1284-90.

6 Hsieh BP, Pham MX, Froelicher VF. Prognostic value of electrocardiographic criteria for left ventricular hypertrophy. Am Heart J 2005;150:161-7.

7 Paolo V, Giuseppe S, Claudia B, et al. Prognostic value of a new electrocardiographic method for diagnosis of left ventricular hypertrophy in essential hypertension. J Am Coll Cardiol 1998;31:383-90.

8 Mentz RJ, Greiner MA, DeVore AD, et al. Ventricular conduction and long-term heart failure outcomes and mortality in African Americans: insights from the Jackson heart study. Circ Heart Fail 2015;8:243-51.

9 Badheka AO, Singh V, Patel NJ, et al. Qrs duration on electrocardiography and cardiovascular mortality (from the National health and nutrition examination Survey-III). Am J Cardiol 2013;112:671-7.

10 Heistaro S. Methodology report : Health 2000 survey. Publications of the National Health Institute B26/2008 2008;2008.

11 Strauss DG, Selvester RH, Wagner GS. Defining left bundle branch block in the era of cardiac resynchronization therapy. Am J Cardiol 2011;107:927-34.

12 Prineas RJ, Crow RS, Zhang Z-M. The Minnesota code manual of electrocardiographic findings. Springer Science \& Business Media, 2009.

13 Casale PN, Devereux RB, Kligfield P, et al. Electrocardiographic detection of left ventricular hypertrophy: development and prospective validation of improved criteria. J Am Coll Cardiol 1985;6:572-80.

14 Pajunen $\mathrm{P}$, Koukkunen $\mathrm{H}$, Ketonen $\mathrm{M}$, et al. The validity of the Finnish hospital discharge register and causes of death register data on coronary heart disease. Eur J Cardiovasc Prev Rehabil 2005:12:132-7.

15 Vuori MA, Laukkanen JA, Pietilä A, et al. The validity of heart failure diagnoses in the Finnish hospital discharge register. Scand J Public Health 2020;48:20-8.

16 Fine JP, Gray RJ. A proportional hazards model for the Subdistribution of a competing risk. J Am Stat Assoc 1999;94:496-509.

17 Aro AL, Anttonen O, Tikkanen JT, et al. Intraventricular conduction delay in a standard 12-lead electrocardiogram as a predictor of mortality in the general population. Circ Arrhythm Electrophysiol 2011:4:704-10

18 Larsen $\mathrm{CT}$, Dahlin J, Blackburn $\mathrm{H}$, et al. Prevalence and prognosis of electrocardiographic left ventricular hypertrophy, St segment depression and negative T-wave; the Copenhagen City heart study. Eur Heart J 2002;23:315-24.

19 Okwuosa TM, Soliman EZ, Lopez F, et al. Left ventricular hypertrophy and cardiovascular disease risk prediction and reclassification in blacks and whites: the Atherosclerosis risk in Communities study. Am Heart J 2015;169:155-61.
20 Jain A, Tandri H, Dalal D, et al. Diagnostic and prognostic utility of electrocardiography for left ventricular hypertrophy defined by magnetic resonance imaging in relationship to ethnicity: the multi-ethnic study of atherosclerosis (MESA). Am Heart $J$ 2010;159:652-8.

21 Okin PM, Devereux RB, Kjeldsen SE. Incidence of heart failure in relation to QRS duration during antihypertensive therapy: the life study. J Hypertens 2009;27:2271-7.

22 Oikarinen L, Nieminen MS, Viitasalo M, et al. Qrs duration and QT interval predict mortality in hypertensive patients with left ventricular hypertrophy: the losartan intervention for endpoint reduction in hypertension study. Hypertension 2004;43:1029-34.

23 Maury P, Lematte E, Derval N, et al. Prevalence and long-term prognosis of patients with 'narrower than normal' QRS complexes. EP Eur 2018:20:692-7.

24 Dhingra R, Ho Nam B, Benjamin EJ, et al. Cross-Sectional relations of electrocardiographic QRS duration to left ventricular dimensions. J Am Coll Cardiol 2005;45:685-9.

25 Krumholz HM, Larson M, Levy D. Sex differences in cardiac adaptation to isolated systolic hypertension. Am J Cardiol 1993;72:310-3

26 Ilkhanoff L, Liu K, Ning H, et al. Association of QRS duration with left ventricular structure and function and risk of heart failure in middleaged and older adults: the multi-ethnic study of atherosclerosis (MESA). Eur J Heart Fail 2012;14:1285-92.

27 Levy D, Garrison RJ, Savage DD, et al. Prognostic implications of echocardiographically determined left ventricular mass in the Framingham heart study. N Engl J Med 1990;322:1561-6.

28 Gardin JM, McClelland R, Kitzman D, et al. M-Mode echocardiographic predictors of six- to seven-year incidence of coronary heart disease, stroke, congestive heart failure, and mortality in an elderly cohort (the cardiovascular health study). Am J Cardiol 2001;87:1051-7.

29 Casale PNet al. Value of echocardiographic measurement of left ventricular mass in predicting cardiovascular morbid events in hypertensive men. Ann Intern Med 1986;105:173-8.

30 Giuseppe S, Paolo V, Carlo P, et al. Continuous relation between left ventricular mass and cardiovascular risk in essential hypertension. Hypertension 2000;35:580-6.

31 Koren MJ, Devereux RB, Casale PN. Relation of left ventricular mass and geometry to morbidity and mortality in uncomplicated essential hypertension. Ann Intern Med 1991;114:345-52.

32 Domain G, Chouquet C, Réant P, et al. Relationships between left ventricular mass and QRS duration in diverse types of left ventricular hypertrophy. Eur Heart J Cardiovasc Imaging 2021;39.

33 Kannel WB. Left ventricular hypertrophy as a risk factor in arterial hypertension. Eur Heart J 1992;13:82-8.

34 Murkofsky RL, Dangas G, Diamond JA, et al. A prolonged QRS duration on surface electrocardiogram is a specific indicator of left ventricular dysfunction. J Am Coll Cardiol 1998;32:476-82.

35 Drazner MH, Rame JE, Marino EK, et al. Increased left ventricular mass is a risk factor for the development of a depressed left ventricular ejection fraction within five years. J Am Coll Cardiol 2004;43:2207-15. 